\title{
Exploring the outcomes and experiences of Black and White athletes following a sport-related concussion: a retrospective cohort study
}

\author{
Aaron M. Yengo-Kahn, MD, ${ }^{1,2}$ Jessica Wallace, PhD, MPH, LAT, ATC, ${ }^{3}$ Viviana Jimenez, MD, MPH, ${ }^{2,4}$ \\ Douglas J. Totten, BA, ${ }^{2,5}$ Christopher M. Bonfield, MD, ${ }^{1,2}$ and Scott L. Zuckerman, MD, MPH ${ }^{1,2}$ \\ 1Department of Neurological Surgery, Vanderbilt University Medical Center; ${ }^{2}$ Vanderbilt Sport Concussion Center, Vanderbilt \\ University Medical Center, Nashville, Tennessee; ${ }^{3}$ Department of Health Science, Athletic Training Program, University of \\ Alabama, Tuscaloosa, Alabama; ${ }^{4}$ Department of Neurology, Vanderbilt University Medical Center; and ${ }^{5}$ Vanderbilt University \\ School of Medicine, Nashville, Tennessee
}

OBJECTIVE Young American athletes, at risk of sport-related concussion (SRC), represent many races; however, it is unknown how race may influence the experience and outcome of SRC. The authors' objective was to compare White and Black athletes' recovery and subjective experiences after SRC.

METHODS A retrospective study was performed using the Vanderbilt Sports Concussion registry. Self-reported White and Black young athletes (ages 12-23 years) who had been treated for SRC between 2012 and 2015 were included. Athletes with learning disabilities or psychiatric conditions were excluded. Data were collected by electronic medical record review and phone calls to athletes and parents or guardians. The primary outcomes were as follows: 1) days to symptom resolution (SR), 2) days to return to school, and changes in 3) any daily activity (binary) and 4) sport behavior (binary). Secondary outcomes were changes (more, unchanged, or less) in specific activities such as sleep, schoolwork, and television time, as well as equipment (binary) or playing style (more reckless, unchanged, or less reckless) and whether the athlete retired from sport. Descriptive analyses, multivariable Cox proportional hazards models, and logistic regression were performed.

RESULTS The final cohort included 247 student-athletes ( 36 Black, 211 White). Black athletes were male (78\% vs 58\%) more often than White athletes, but both races were similar in age, sport, and medical/family histories. Black athletes more frequently had public insurance (33.3\% vs $5.7 \%$ ) and lived in areas with a low median income ( $41.2 \%$ vs $26.6 \%)$. After adjusting for age, sex, concussion history, insurance status, and zip code median income, Black athletes reached an asymptomatic status ( $\mathrm{HR} 1.497,95 \% \mathrm{Cl} 1.014-2.209, \mathrm{p}=0.042)$ and returned to school earlier ( $\mathrm{HR} 1.522,95 \% \mathrm{Cl}$ $1.020-2.270, p=0.040$ ). Black athletes were less likely to report a change in any daily activity than White athletes (OR $0.368,95 \% \mathrm{Cl} 0.136-0.996, p=0.049$ ). Changes in sport behavior were comparable between the groups.

CONCLUSIONS Racial differences appear to exist in the outcomes and experience of SRC for young athletes, as Black athletes reached SR and return to school sooner than White athletes. Race should be considered as an important social determinant in SRC treatment.

https://thejns.org/doi/abs/10.3171/2021.2.PEDS2130

KEYWORDS racial disparities; health equity; concussion; sports; social determinant; trauma

A PPROXIMATELY 38 million children and adolescents participate in organized sports annually, ${ }^{1}$ and as high as $20 \%$ of these young athletes report a previous concussion. ${ }^{2}$ Risk factors for a prolonged recovery after sport-related concussion (SRC) include prior concussion, ${ }^{3}$ female sex, ${ }^{4}$ attention deficit hyperactivity disorder (ADHD) or learning disability (LD) diagnosis, ${ }^{5}$ migraines, ${ }^{6}$ and psychiatric histories. ${ }^{7}$ However, the asso- ciation between race and SRC outcomes remains understudied despite a foundation of literature demonstrating racial disparities in healthcare outcomes and quality of life across medicine. ${ }^{8,9}$ Furthermore, Black athletes make up $16 \%$ of collegiate athletes across all three National Collegiate Athletic Association (NCAA) divisions..$^{10}$ It is also estimated that nearly 2 out of 3 Black high school students participate in sport; however, there are flaws in the count-

ABBREVIATIONS ADHD = attention deficit hyperactivity disorder; $E D=$ emergency department; $E H R$ = electronic health record; $L D=$ learning disability; $R T L=$ return to learn; $\mathrm{SR}=$ symptom resolution; SRC $=$ sport-related concussion.

SUBMITTED January 13, 2021. ACCEPTED February 23, 2021.

INCLUDE WHEN CITING Published online August 24, 2021; DOI: 10.3171/2021.2.PEDS2130. 
ing methods used, and exact participation values are unknown. ${ }^{11}$

In the United States, race is a complex social determinant identified throughout population health, including in education, community contexts, healthcare, neighborhood environments, and economic stability. ${ }^{12}$ Disparities in these resources can lead to populations that demonstrate poorer general and mental health outcomes and represent persistent barriers to health equality. ${ }^{12,13}$ At the individual level, racism or the experience of racial inequality can have negative psychological and physiological effects; at the institutional level, inequities perpetuated by institutions and health providers lead to inequalities in access to and the quality of care. ${ }^{14,15}$ Moreover, racial biases in social, school, and community support have been clearly linked to inequalities in the basic needs of youth and adolescents, such as physical activity and sport availability. ${ }^{15,16}$ Thus, the interaction of race with health outcomes requires consistent attention and deliberate study.

To date, few SRC-related studies have included race. Prior studies have predominantly focused on differences in baseline neurocognitive measures, wherein Black athletes appear to have poorer baseline and postconcussion neurocognitive test scores than White athletes, and these disparities are credited to inequities in quality of education and healthcare access and a lack of diverse representation in the creation of normative values. ${ }^{17-20}$ Racial disparities have also been described in access to care. Compared to White athletes, non-White youth were more likely to seek SRC care through the emergency department (ED) ${ }^{21}$ and also to leave the ED prematurely without being seen by a medical provider, perhaps because of congested, overcrowded EDs and long wait times. ${ }^{22}$ While these early studies suggest the importance of understanding race as a chief social determinant of health and a potential modifying factor of SRC care, differences in recovery and the subjective experience of concussion remain understudied.

Evaluating the relationship between race and concussion experience may allow for a deeper therapeutic understanding between providers and athletes to improve the management of SRC. In a cohort of student-athletes seen at a regional SRC center, our objective was to compare White and Black athletes after SRC in the outcomes of 1) time to symptom resolution (SR), 2) time to return to school, and changes in 3) daily activity and 4) sport behavior.

\section{Methods Study Design}

A retrospective cohort study was conducted using the Vanderbilt Sports Concussion Center outcome registry database, with approval obtained from the Vanderbilt University Institutional Review Board. Registry construction and data collection have been described elsewhere. ${ }^{23}$ All patients incurred an SRC and were evaluated by a team of interdisciplinary providers between January 1, 2012, and May 31, 2015. Each SRC diagnosis was confirmed according to the most up-to-date Concussion In Sport Group (CISG) definition at the time of collection. ${ }^{24}$ Written informed consent for serial phone interviews and medical record review was provided by participants and guardians. All data were maintained in a secure, de-identified electronic database.

\section{Study Population}

All registry athletes $(n=699)$ were screened, and 297 $(42.5 \%)$ were eligible for inclusion after those with incomplete interview data had been removed $(n=402)$. The study population included middle school, high school, and collegiate student-athletes in the middle Tennessee, northern Alabama, and southern Kentucky region with ages between 12 and 23 years. The following athletes were excluded: those who did not report Black or White race (n $=5)$ and those with ADHD/LD $(\mathrm{n}=32)$ or depression/ anxiety and/or a psychiatric disorder $(n=9$; Fig. 1$)$. These athletes were excluded because these comorbidities are recognized as potentially confounding. ${ }^{3,7}$ Those older than 23 years $(n=4)$ were also excluded. The final group was dichotomized by self-reported race as Black or White.

\section{Data Collection}

As previously published, standardized phone interviews were used to retrospectively collect patient and SRC information. ${ }^{23}$ All patients were contacted 3 months after the initial concussion to allow for SR. If a patient remained symptomatic at the time of the initial interview, additional contacts were made until symptoms had resolved or 1 year had passed postinjury. For patients younger than 18 years of age, parents and/or guardians were interviewed alongside the patient to provide corroborating information concerning the SRC. Independent variables included demographics, past medical history, family history, and concussion history. Sports in which SRCs had occurred were recorded, and these were categorized by contact level as defined by the American Academy of Pediatrics (AAP). ${ }^{25}$ Zip codes were recorded, and corresponding median adjusted gross income was categorized into three groups based on percentiles ( 0 to 59 th, 60 th to 79 th, and $\geq 80$ th), similar to prior studies. ${ }^{23}$ Insurance status was recorded and categorized as private or public. Institutional electronic health records (EHRs) were used to cross-validate interview data. Discrepancies between patient interviews and EHR data were resolved through additional patient contacts.

\section{Outcomes}

Four primary outcomes were considered. The two continuous primary outcomes were time until SR and time until return to school, termed "return to learn" (RTL) among all participants as all were enrolled in middle school, high school, or college. Time to SR was defined as the number of days from initial injury to the time when all concussion-related symptoms had dissipated, according to the athlete. RTL was measured as the number of missed school days (i.e., weekends not included) attributable to the injury and was not recorded if the SRC had occurred during the no-school summertime period $(n=3)$. An athlete was considered returned to school when either half or full days were resumed.

The two remaining primary outcomes were categori- 


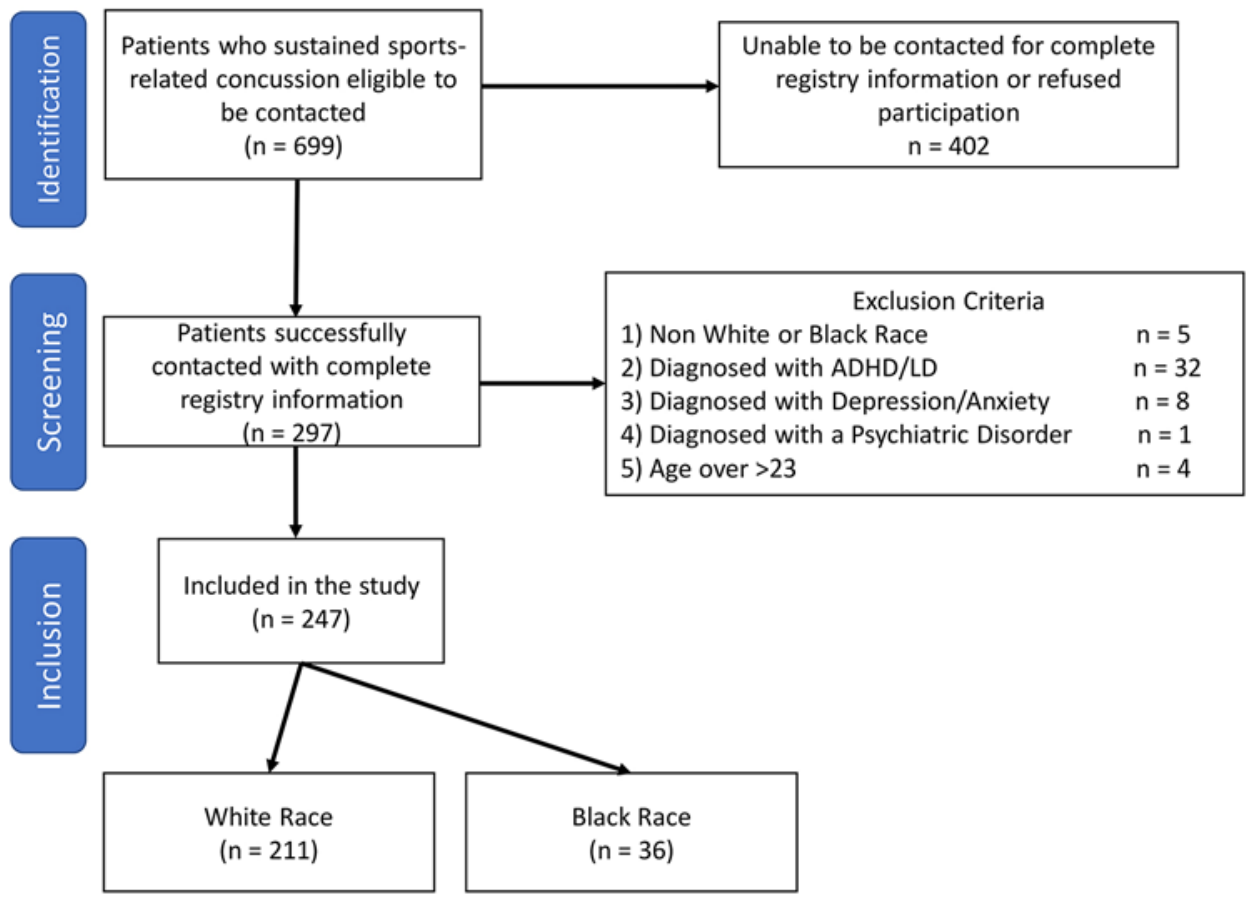

FIG. 1. Patient flow diagram. Figure is available in color online only.

cal, that is, whether they changed any daily activities or any sport behaviors following SRC. If athletes reported a change in activity post-SRC, they were asked specifically whether they had experienced changes (more, unchanged, or less) in the time spent sleeping, watching television, doing schoolwork, or playing video games. Athletes reporting a change in sport behavior were asked specifically to recall changes in playing style (i.e., more reckless, unchanged, or less reckless) or protective equipment (i.e., helmet, mouthguard) and/or whether they had stopped playing the sport associated with the injury altogether (retired). Athletes were able to report multiple changes for activities and sport behavior, and these responses were not considered mutually exclusive.

\section{Statistical Analysis}

Descriptive statistics were reported as frequencies and proportions for categorical variables and means \pm standard deviations for continuous variables. Median times to SR and RTL were compared between groups using MannWhitney U-tests, after examination of quantile-quantile (Q-Q) plots suggested nonnormally distributed data.

Multivariable Cox proportional hazards models were used to assess the relationship of race and time to SR as well as RTL while controlling for the potentially confounding covariates of age, sex, previous concussion history, insurance status, and zip code median income percentile group. ${ }^{3,23}$ The covariates were selected a priori based on prior literature ${ }^{3,23}$ while respecting the maximum allowable number of covariates to prevent model overfitting based on the number of uncensored events. ${ }^{26}$ Athletes who had not attained SR or RTL at the time of the interview were censored at that point. Extreme outliers, defined as values more than 3 times IQR greater than the third quartile, were also censored at that limit. Those with missing SR $(n=6)$ or RTL $(n=3)$ data were excluded from these analyses. All variables were entered into a single model for each outcome; no stepwise iterative methods were used. All hazard ratios with $95 \%$ confidence intervals not containing 1.0 were considered statistically significant.

For the post-SRC behavior analysis, the general outcomes of any daily activity change and any sport behavior change were chosen for multivariable logistic regression analyses. As above, covariates were chosen a priori based on prior literature demonstrating their importance in SRC outcomes while remaining well under the maximum explanatory variables defined as one variable per ten of the rarest outcome events. ${ }^{3,26}$ These were age, sex, concussion history, and zip code median income percentile group. Insurance status was omitted from these models, as we considered it to be unrelated to daily activity and sport behavior choices, whereas the other variables represent factors that may affect how an individual copes with illness in terms of personal choices and the resources potentially available (based on income). Testing of statistical significance was reserved for primary outcomes. Statistical significance was determined at a level of $p<0.05$. All statistical analysis was performed using SPSS version 27 (IBM Corp.).

\section{Results}

\section{Patient Demographic Data}

The final cohort included 247 student-athletes (211 White, 36 Black; Table 1). In both groups, the majority of athletes were male $(57.8 \%$ White males, $77.8 \%$ Black 
TABLE 1. Biopsychosocial characteristics

\begin{tabular}{|c|c|c|}
\hline Variable & White & Black \\
\hline No. of student-athletes & 211 & 36 \\
\hline \multicolumn{3}{|l|}{ Demographics } \\
\hline Mean age in yrs & $15.9 \pm 2.05$ & $16.1 \pm 1.9$ \\
\hline Male & $122(57.8)$ & $28(77.8)$ \\
\hline \multicolumn{3}{|l|}{ Sport contact level ${ }^{*}$} \\
\hline Contact & $186(89.4)$ & $32(94.1)$ \\
\hline Limited contact & $19(9.1)$ & $2(5.9)$ \\
\hline Noncontact & $3(1.4)$ & $0(0)$ \\
\hline \multicolumn{3}{|l|}{ Past medical \& family histories } \\
\hline Previous concussion & $71(33.6)$ & $11(30.6)$ \\
\hline Migraine & $35(16.6)$ & $6(16.7)$ \\
\hline Family history of migraine & $69(32.7)$ & $10(27.8)$ \\
\hline Family history of depression or anxiety & $35(16.6)$ & $2(5.6)$ \\
\hline $\begin{array}{l}\text { Family history of other psychiatric } \\
\text { disorder }\end{array}$ & $45(21.3)$ & $7(19.4)$ \\
\hline \multicolumn{3}{|l|}{ Socioeconomic status } \\
\hline \multicolumn{3}{|l|}{ Insurance } \\
\hline Private & $199(94.3)$ & $24(66.7)$ \\
\hline Public/Medicaid & $12(5.7)$ & $12(33.3)$ \\
\hline \multicolumn{3}{|l|}{ Zip code median income percentile† } \\
\hline$\geq 80$ th & $115(55.6)$ & $7(20.6)$ \\
\hline 60th-79th & $37(17.9)$ & $13(38.2)$ \\
\hline $0-59$ th & $55(26.6)$ & $14(41.2)$ \\
\hline
\end{tabular}

Values expressed as mean \pm standard deviation or as number (\%).

* Data missing for 3 White athletes and 2 Black athletes.

† Data missing for 4 White athletes and 2 Black athletes.

males) and of adolescent age. The age distributions were similar between groups. Approximately $90 \%$ each of Black and White athletes were involved in contact sports. The two groups were similar in terms of past medical and family histories. A greater proportion of White athletes had private insurance compared to Black athletes (94\% vs $67 \%$ ). Most White athletes $(56 \%)$ were in the $\geq 80$ th percentile for median income, whereas Black athletes (41\%) were most frequently in the $0-59$ th median income percentile.

\section{Symptom Resolution}

The median time to SR for White athletes was 21.0 days (IQR 10.5-61.0) compared to 12.3 days (IQR 6.828.0) for Black athletes $(p=0.026)$. Controlling for age, sex, concussion history, median income, and insurance type, multivariable Cox regression revealed that Black athletes recovered or reached asymptomatic status sooner than White athletes (HR 1.497, 95\% CI 1.014-2.209, p $=0.042$; Table 2 and Fig. 2). Also, male athletes reached asymptomatic status earlier than females (HR 1.508, 95\% CI $1.140-1.996, \mathrm{p}=0.004)$.

\section{Return to Learn}

The RTL was 2 school days (IQR 0-5) missed for White athletes compared to 0 days (IQR 0-2) for Black athletes $(p=0.010)$. Controlling for age, sex, concussion history, median income, and insurance type, multivariable Cox regression revealed that Black race (HR 1.522, 95\% CI $1.020-2.270, \mathrm{p}=0.040$ ) was independently associated with returning to school sooner postinjury than White race (Table 2 and Fig. 3). Also, athletes living in zip codes with median incomes between the 60th and 79th percentiles returned to school earlier than those in the lowest income tier (HR 1.506, 95\% CI 1.017-2.232, $\mathrm{p}=0.041)$.

\section{Activity Profiles}

Few notable differences were demonstrated between the groups' postconcussion daily activity profiles (Table $3)$. White athletes more frequently reported sleeping less (19.0\% vs 5.6\%), doing less schoolwork (57.8\% vs $41.7 \%$ ), and watching less television (63.5\% vs $52.8 \%$ ) than before their concussion compared to Black athletes. After adjusting for age, sex, concussion history, and zip code median income, Black race was shown to be independently associated with lower odds of reporting any activity change after concussion (OR 0.368, 95\% CI 0.136-0.996, $\mathrm{p}=0.049$; Table 4).

Black athletes more frequently reported a change in protective equipment (25.0\% vs $12.3 \%$ ) compared to White athletes (Table 3). Of those Black athletes who changed equipment, 4 (44.4\%) played basketball, 4 (44.4\%) played football, and $1(11.1 \%)$ played soccer. Of those White athletes who changed equipment, 2 (7.7\%) played basketball, $16(61.5 \%)$ played football, and $6(23 \%)$ played soccer. The remainder were spread across several sports. After adjusting for age, sex, concussion history, and zip code median income, Black race was not independently associated with a sport behavior change after concussion (OR 0.923, 95\% CI 0.424-2.011, $\mathrm{p}=0.84$; Table 4).

\section{Discussion}

The current findings suggest a relationship between race and symptom duration, school days missed, and changes to post-SRC activity and some aspects of sport behavior. After adjusting for multiple demographic variables, we found that Black athletes experienced a shorter duration of symptoms and returned to school quicker than their White peers. Specifically, the median days to SR among Black athletes was 12 days compared to 21 days among White athletes. Moreover, Black athletes were less likely to report changes in their post-SRC daily activity than White athletes. Knowing that SRC can cause an array of symptoms and interfere with daily life, the findings from this study provide novel evidence that the recovery experience following SRC likely differs between Black and White athletes, and understanding these differences may serve to provide better and more personalized intervention and management strategies.

\section{Time to SR}

Black athletes were found to experience SR sooner than White athletes. Several premorbid modifiers have been identified as contributing to symptomology and/or prolonged symptomology, yet there are limited data on social determinants, including race. ${ }^{3}$ Subjective symp- 
TABLE 2. Multivariable Cox regressions for SR and RTL

\begin{tabular}{|c|c|c|c|c|c|c|}
\hline \multirow[b]{2}{*}{ Factor } & \multicolumn{3}{|c|}{ SR } & \multicolumn{3}{|c|}{ RTL } \\
\hline & $\mathrm{HR}$ & $95 \% \mathrm{Cl}$ & $p$ Value & $\mathrm{HR}$ & $95 \% \mathrm{Cl}$ & $p$ Value \\
\hline \multicolumn{7}{|l|}{ Race } \\
\hline Black & 1.497 & $1.014-2.209$ & 0.042 & 1.522 & $1.020-2.270$ & 0.040 \\
\hline White & REF & - & - & REF & - & - \\
\hline $\mathrm{Age}^{*}$ & 0.947 & $0.887-1.011$ & 0.10 & 0.994 & $0.935-1.057$ & 0.86 \\
\hline \multicolumn{7}{|l|}{ Prior concussions } \\
\hline $1+$ & 1.000 & $0.746-1.341$ & $>0.99$ & 1.029 & $0.774-1.367$ & 0.85 \\
\hline 0 & REF & - & - & REF & - & - \\
\hline \multicolumn{7}{|l|}{ Insurance } \\
\hline Private & 1.161 & $0.704-1.915$ & 0.56 & 0.763 & $0.456-1.277$ & 0.303 \\
\hline Public & REF & - & - & REF & - & - \\
\hline \multicolumn{7}{|l|}{ Sex } \\
\hline Male & 1.508 & $1.140-1.996$ & 0.004 & 1.213 & $0.925-1.591$ & 0.16 \\
\hline Female & REF & - & - & REF & - & - \\
\hline \multicolumn{7}{|c|}{ Zip code median income percentile } \\
\hline$\geq 80$ th & 1.212 & $0.853-1.722$ & 0.28 & 1.412 & $0.987-2.018$ & 0.06 \\
\hline 60th-79th & 1.071 & $0.728-1.576$ & 0.73 & 1.506 & $1.017-2.232$ & 0.041 \\
\hline $0-59$ th & REF & - & - & REF & - & - \\
\hline
\end{tabular}

REF = reference.

Boldface type indicates statistical significance.

* Per 1-year increments.

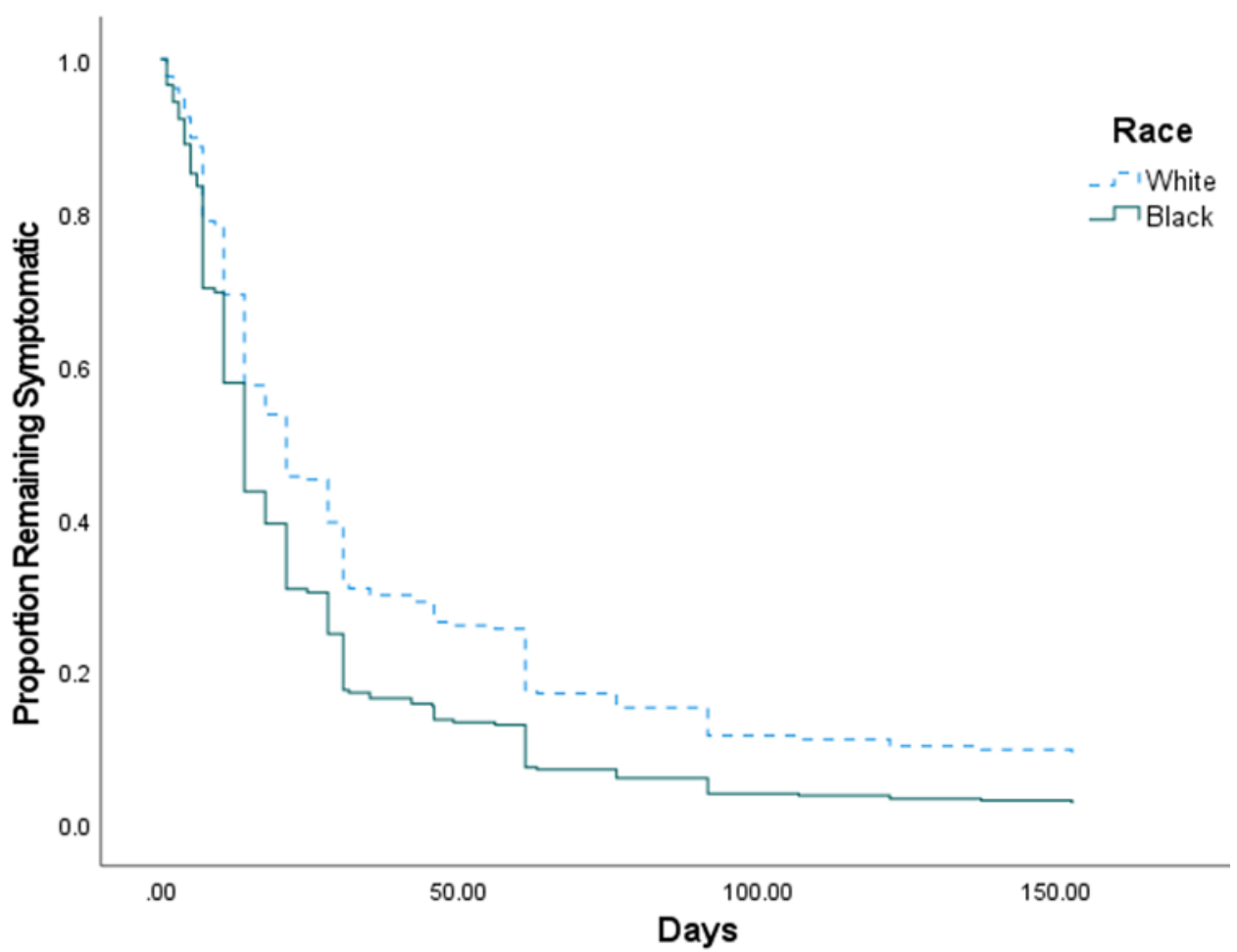

FIG. 2. Survival plot of time to SR by race subgroups. Adjusted for age, sex, prior concussion history, zip code median income, and insurance type, Black athletes were more likely to report SR at any given time than were White athletes (HR 1.497, $p=0.042$ ). Figure is available in color online only. 


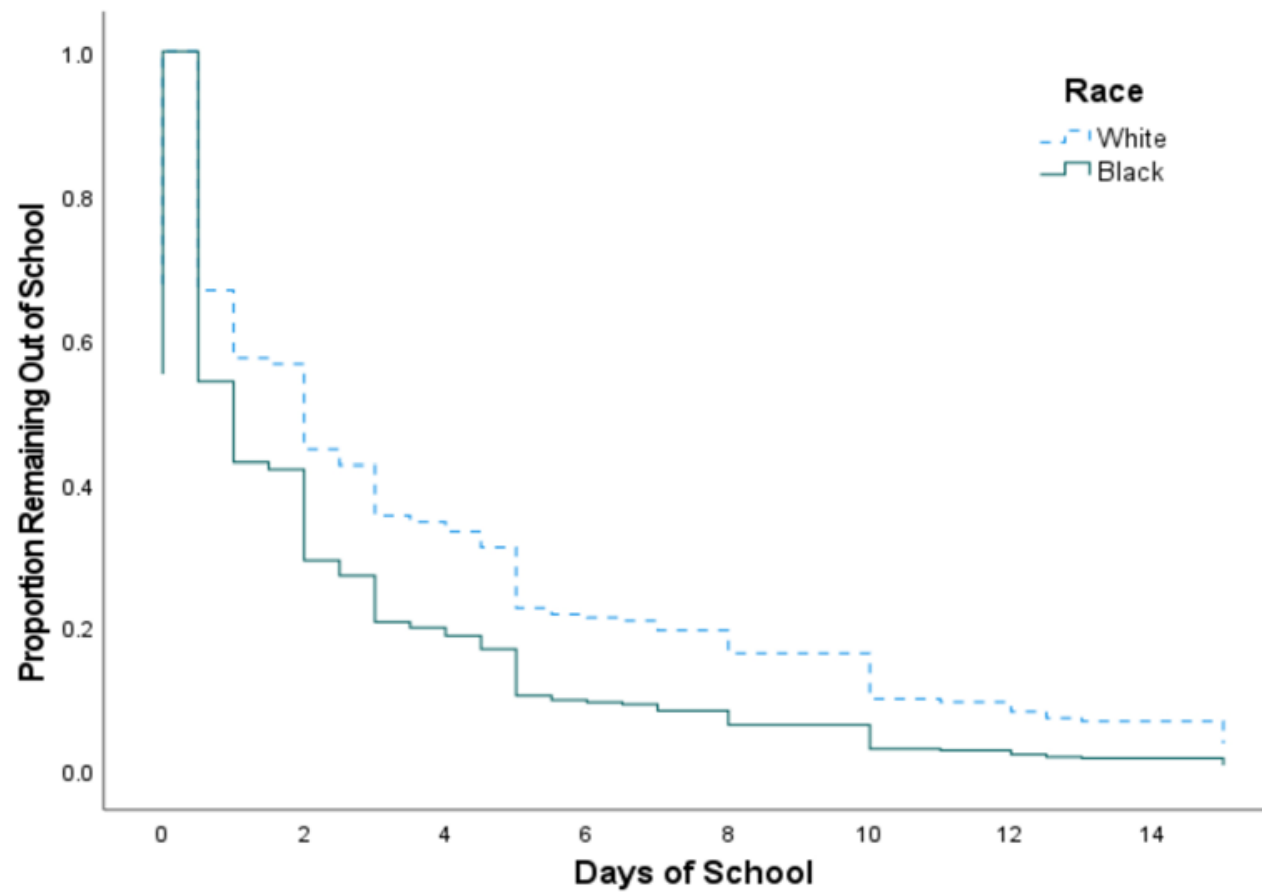

FIG. 3. Survival plot of time to return to school by race subgroups. Adjusted for age, sex, prior concussion history, zip code median income, and insurance type, Black athletes were more likely to be back in school at any given time than were White athletes (HR $1.522, p=0.040)$. Figure is available in color online only.

tom experiences following SRC may differ by race. In a study of 1429 children seen for SRC, Black youth had 77\% greater odds of reporting cognitive-related symptoms following SRC in relation to White youth. ${ }^{27}$ Moreover, a typical time to SR can be around 3-4 weeks, ${ }^{28,29}$ suggesting that White athletes in the current study followed a typical recovery course, but faster recovery occurred in Black athletes. These findings are supported by another recent

TABLE 3. Activity and sport behavior following injury

\begin{tabular}{lcc}
\hline \multicolumn{1}{c}{ Variable } & White & Black \\
\hline No. of athletes & 211 & 36 \\
\hline Daily activities & & \\
\hline Any activity change & $185(87.7)$ & $27(75.0)$ \\
\hline Slept more & $73(34.6)$ & $10(27.8)$ \\
\hline Slept less & $40(19.0)$ & $2(5.6)$ \\
\hline More television & $5(2.4)$ & $1(2.8)$ \\
\hline Less television & $134(63.5)$ & $19(52.8)$ \\
\hline More schoolwork & $5(2.4)$ & $3(8.3)$ \\
\hline Less schoolwork & $122(57.8)$ & $15(41.7)$ \\
\hline More video games & $3(1.4)$ & $1(2.8)$ \\
\hline Less video games & $99(46.9)$ & $17(47.2)$ \\
\hline Sport behaviors & & \\
\hline Any sport behavior change & $112(53.1)$ & $20(55.6)$ \\
\hline Less reckless & $80(37.9)$ & $16(44.4)$ \\
\hline Changed protective equipment & $26(12.3)$ & $9(25.0)$ \\
\hline Stopped playing offending sport & $39(18.5)$ & $4(11.1)$ \\
\hline
\end{tabular}

study of 227 young athletes demonstrating earlier returnto-play clearance for Hispanic or African American male athletes. ${ }^{30}$

Aside from these few previous studies, it is difficult to contextualize our findings mainly because of the underreporting of race in major studies of pediatric mild traumatic brain injury and SRC. Notably, a large study that provided the current understanding of natural symptom progression after concussion stratified results by age and sex but did not report race. ${ }^{29}$ Similarly, another large study proposing a risk stratification system for prolonged recovery did not consider race as a covariate, nor reported it.$^{28}$ Finally, these omissions are not limited to large retrospective studies, as a recent, highly publicized randomized controlled trial of early exercise treatment for SRC did not report the race of its participants. ${ }^{31}$ These pertinent omissions highlight systemic underreporting that contributes to our limited understanding of race and SRC.

The observed shorter SR among the Black athletes may be explained by a complex interplay among race, concussion knowledge, ${ }^{32}$ attitudes toward SRC, ${ }^{33}$ reporting behavior, ${ }^{34}$ and sociodemographic disparities. ${ }^{35}$ Previous research has shown that Black athletes have less concussion symptom knowledge than their White peers, and this disparity widens in the absence of an athletic trainer, which can occur in less resourced schools. ${ }^{32}$ Further, Black athletes have been reported to have less serious attitudes about concussions than White athletes, ${ }^{33}$ which likely contributes to disparities in concussion reporting, with Black athletes reporting $18 \%-33 \%$ less than White peers. ${ }^{34} \mathrm{In}$ the present study, a larger percentage of the Black athletes (41.2\% vs $26.6 \%)$ fell within the lowest household income 
TABLE 4. Multivariable logistic regressions for any change in daily activities or sport behavior

\begin{tabular}{|c|c|c|c|c|c|c|}
\hline \multirow[b]{2}{*}{ Factor } & \multicolumn{3}{|c|}{ Any Activity Change } & \multicolumn{3}{|c|}{ Any Sport Behavior Change } \\
\hline & OR & $95 \% \mathrm{Cl}$ & $p$ Value & OR & $95 \% \mathrm{Cl}$ & $p$ Value \\
\hline \multicolumn{7}{|l|}{ Race } \\
\hline Black & 0.368 & $0.136-0.996$ & 0.049 & 0.923 & $0.424-2.011$ & 0.84 \\
\hline White & REF & - & - & REF & - & - \\
\hline Age $^{*}$ & 1.012 & $0.840-1.220$ & 0.90 & 1.153 & $1.009-1.317$ & 0.037 \\
\hline \multicolumn{7}{|l|}{ Prior concussions } \\
\hline $1+$ & 0.532 & $0.246-1.151$ & 0.11 & 0.836 & $0.476-1.467$ & 0.532 \\
\hline 0 & REF & - & - & REF & - & - \\
\hline \multicolumn{7}{|l|}{ Sex } \\
\hline Male & 0.481 & $0.203-1.141$ & 0.10 & 0.928 & $0.543-1.585$ & 0.78 \\
\hline Female & REF & - & - & REF & - & - \\
\hline \multicolumn{7}{|c|}{$\begin{array}{l}\text { Zip code median income } \\
\text { percentile }\end{array}$} \\
\hline$\geq 80$ th & 0.323 & $0.097-1.078$ & 0.07 & 0.510 & $0.250-1.040$ & 0.06 \\
\hline 60th-79th & 0.578 & $0.161-2.075$ & 0.40 & 0.636 & $0.297-1.363$ & 0.25 \\
\hline $0-59$ th & REF & - & - & REF & - & - \\
\hline
\end{tabular}

Boldface type indicates statistical significance.

* Per 1-year increments.

group compared to White athletes, and a larger percentage of Black athletes (33.3\% vs 5.7\%) had public insurance. In concert with previous findings, the self-reported SR in the present study could be a product of these noted disparities.

\section{Time to Return to School}

Another key finding from the present study was the quicker return to school among Black athletes. To our knowledge, no studies have evaluated racial differences in RTL following SRC; however, previous research has shown that individuals with private insurance were slower to return to school than individuals with public insurance. ${ }^{23}$ After adjusting for variables of insurance status, sex, age, prior concussion history, and median household income, Black athletes were $50 \%$ more likely than White athletes to return to school sooner following their SRC. This finding suggests that race may play more of a role in return-to-school decisions than insurance status or other proxies of socioeconomic status. Again, these racial differences can potentially be explained by sociocultural differences between Black and White communities, access to school professionals suited to monitor academic progress ${ }^{36}$ or knowledge and attitude disparities.

Returning to school following SRC is receiving increased attention; however, currently there exists substantial variability in RTL definitions and methodologies, causing confusion in the field. ${ }^{37}$ The Centers for Disease Control and Prevention suggests that youths with SRC can return to school within 2-3 days after an injury, ${ }^{38}$ but studies demonstrate disparate timelines in full RTL, ranging from 0 days ${ }^{39}$ to 35 days ${ }^{40}$ Furthermore, practice patterns vary from half-day return to full-day return to individual, customized learning plans for each athlete. Concussion consensus statements denote that RTL should be completed in stage 2 of recovery and that the timeline for reentry will likely vary for each individual. ${ }^{41}$ Accepting that these guidelines allow for variability, RTL timelines may be particularly susceptible to sociocultural differences in interpretation and application. Results from our study suggest that students are potentially returning to school at an accelerated rate compared to consensus guidelines, and, in particular, Black athletes are returning to school upwards of 2 days sooner than White athletes. Several sociodemographic differences may underlie this finding, warranting further investigation into equitable and appropriate accommodations. ${ }^{42}$ With faster reentry, Black athletes may not be receiving an adequate initial period of cognitive rest or academic accommodations. Further, in our study, more Black athletes reported having increased schoolwork, whereas more White athletes stated that they had less schoolwork during their recovery. Thus, it is difficult to conclude whether a quicker return to school aids in a quicker resolution of symptoms or whether SR allows for a quicker return to school. More research is needed to better understand the relationship between return to school and SR among racial groups.

\section{Changes in Daily Activity and Sport Behavior}

Adjusted analyses aimed at understanding the relationship between race and changes in daily activity showed that Black athletes were more than $60 \%$ less likely than their White peers to report a change in their daily activity. Activities considered in this study were sleeping, watching television, doing schoolwork, and playing video games. Previous qualitative research with adolescents has shown that four categories-school, mood, and physical and social activities-emerged when asking how SRC symptoms affected aspects of life..$^{43}$ In addition, the ability to control environmental symptom-exacerbating factors, such as noise levels and bright lights, led to different strategies to self-manage symptoms. ${ }^{43}$ Among the athletes in this study, there were small differences between Black and White ath- 
letes in video game use, but a greater proportion of White athletes reported that they slept more $(34.6 \%$ vs $27.8 \%)$ and watched less television $(63.5 \%$ vs $52.8 \%)$ than the proportion of Black athletes. The median duration of sleep disturbance following SRC has been shown to be approximately 16 days, ${ }^{44}$ and the sleep changes reported among the White athletes could be tied to their longer symptom duration. While the SRC experience is unique for each individual, contextualizing this experience in harmony with social determinants of health may provide evidence for patterns of recovery among patients from diverse groups.

Nearly $13 \%$ more Black athletes reported making a protective equipment change, whereas $7 \%$ more White athletes reported stopping participation in the offending sport. After accounting for demographic variables, making modifications to sport behaviors did not differ between Black and White athletes. However, the odds of a sport behavior change increased with each yearly increase in age, suggesting that as the athletes matured, they made a behavior change that could be considered a safety precaution. This finding sparks interest in that behavior changes were seen across both Black and White athletes, yet further inquiry is needed in future studies to fully contextualize and understand these changes.

\section{Considerations for the Future}

One's race may impact how they navigate healthcare spaces and their accessibility to physicians and support resources, as well as their experiences with illness and recovery (i.e., return to activities). However, a vast majority of SRC studies include racially and ethnically homogeneous samples, do not report race, or report race but do not utilize it as a covariate. These shortcomings present challenges for clinicians to fully appreciate how race, as a social determinant of health, may affect risk, recovery, and long-term sequelae. Thus, equalizing SRC education and healthcare resources, recruiting diverse samples, and systematically reporting race as well as considering it in analyses will make future findings more equitable and generalizable to underrepresented populations. Toward accomplishing these goals, researchers should consider three immediate steps: 1) integrate themselves directly into schools to avoid biasing study cohorts to only those who have access to multidisciplinary concussion clinics or who seek care in the ED, 2) ensure study cohorts contain racial diversity similar to that in their surrounding community, and 3) consider whether race should be included as a covariate during study design and ensure that it is appropriately collected.

\section{Study Limitations}

This study has several limitations. First, all outcome measures were subjective and retrospectively assessed; thus, findings cannot be extended outside of an outpatient concussion center. Given the nature of data collection, there is the possibility of recall bias in response to items assessed, especially for items such as activity changes. However, data were verified by the research team as best as possible through the review of EHRs, and the amount of time between injury and initial contact did not exceed 3 months. There was an unbalanced number of Black and
White athlete participants; however, this distribution generally aligns with census data in the surrounding metropolitan and county areas. ${ }^{45}$ It is also possible that the low number of Black athletes reflects a disparity in healthcare system utilization. Therefore, while a more robust balance is desirable for future prospective studies, investigators must consider enrolling athletes directly from schools rather than from within the concussion clinic only. Further, race was self-reported based on how each individual identified. We consider this a study strength because there were no predefined choices requiring participants to choose one, and racial classification was not assumed. In addition, although questions were asked regarding equipment changes, qualitative answers as to what specific equipment changes were made were unfortunately not recorded. Similarly, of those who had a previous concussion, we did not record the time interval between an athlete's most recent prior concussion and the indexed concussion, nor did we record the length of recovery time for their most recent prior concussion. These variables may be more important in estimating time to SR than simply whether or not an individual has had a prior concussion, yet it is not clear that including these variables would have altered the results. Finally, zip codes were used to determine median household income, which was used as the proxy for socioeconomic status. There are inherent weaknesses in using this measure because of residential segregation and an inability to capture within-group variability.

\section{Conclusions}

Findings from this study demonstrate that race is an important variable in understanding recovery and the subjective experience of athletes following SRC. Black athletes reported shorter symptom durations and fewer school days missed. Black athletes were also less likely to adjust their daily activities after SRC than White athletes. Understanding the mechanisms of these differences is important for providing effective management strategies and reinforces the necessity of diverse study cohorts going forward.

\section{References}

1. Refakis CA, Turner CD, Cahill PJ. Sports-related concussion in children and adolescents. Clin Spine Surg. 2017;30(5): 191-196.

2. Veliz P, Eckner JT, Zdroik J, Schulenberg JE. Lifetime prevalence of self-reported concussion among adolescents involved in competitive sports: a national U.S. study. J Adolesc Health. 2019;64(2):272-275.

3. Iverson GL, Gardner AJ, Terry DP, et al. Predictors of clinical recovery from concussion: a systematic review. $\mathrm{Br} \mathrm{J}$ Sports Med. 2017;51(12):941-948.

4. Zuckerman SL, Apple RP, Odom MJ, et al. Effect of sex on symptoms and return to baseline in sport-related concussion. J Neurosurg Pediatr. 2014;13(1):72-81.

5. Cook NE, Iaccarino MA, Karr JE, Iverson GL. Attentiondeficit/hyperactivity disorder and outcome after concussion: a systematic review. J Dev Behav Pediatr. 2020;41(7): $571-582$.

6. Terry DP, Huebschmann NA, Maxwell BA, et al. Preinjury migraine history as a risk factor for prolonged return to school and sports following concussion. J Neurotrauma. 2018;36:1. 
7. Legarreta AD, Brett BL, Solomon GS, Zuckerman SL. The role of family and personal psychiatric history in postconcussion syndrome following sport-related concussion: a story of compounding risk. J Neurosurg Pediatr. 2018;22(3):238-243.

8. Ferdows NB, Aranda MP, Baldwin JA, et al. Assessment of racial disparities in mortality rates among older adults living in US rural vs urban counties from 1968 to 2016. JAMA Netw Open. 2020;3(8):e2012241.

9. Wallander JL, Fradkin C, Elliott MN, et al. Racial/ethnic disparities in health-related quality of life and health status across pre-, early-, and mid-adolescence: a prospective cohort study. Qual Life Res. 2019;28(7):1761-1771.

10. NCAA demographics database. NCAA. Published December 13, 2018. Accessed April 16, 2021. http://www.ncaa.org/ about/resources/research/ncaa-demographics-database

11. Women's Sports Foundation. The State of High School Sports in America. An Evaluation of the Nation's Most Popular Extracurricular Activity. Women's Sports Foundation; 2019. Accessed April 16, 2021. https://www. womenssportsfoundation.org/wp-content/uploads/2019/10/ state-of-high-school-sports-report-final.pdf

12. National Academies of Sciences, Engineering, and Medicine. The State of Health Disparities in the United States. National Academies Press; 2017.

13. Paradies Y, Ben J, Denson N, et al. Racism as a determinant of health: a systematic review and meta-analysis. PLoS One. 2015;10(9):e0138511.

14. Stanley J, Harris R, Cormack D, et al. The impact of racism on the future health of adults: protocol for a prospective cohort study. BMC Public Health. 2019;19(1):346.

15. Bailey ZD, Krieger N, Agénor M, et al. Structural racism and health inequities in the USA: evidence and interventions. Lancet. 2017;389(10077):1453-1463.

16. Hasson RE. Addressing disparities in physical activity participation among African American and Latino youth. Kinesiol Rev (Champaign). 2018;7(2):163-172.

17. Kontos AP, Elbin RJ III, Covassin T, Larson E. Exploring differences in computerized neurocognitive concussion testing between African American and White athletes. Arch Clin Neuropsychol. 2010;25(8):734-744.

18. Wallace J, Covassin T, Moran R, Deitrick JM. Factors contributing to disparities in baseline neurocognitive performance and concussion symptom scores between black and white collegiate athletes. $J$ Racial Ethn Health Disparities. 2018;5(4):894-900.

19. Wallace J, Moran R, Beidler E, et al. Disparities on baseline performance using neurocognitive and oculomotor clinical measures of concussion. Am J Sports Med. Published online August 17, 2020. doi:10.1177/0363546520946753

20. Houck Z, Asken B, Clugston J, et al. Socioeconomic status and race outperform concussion history and sport participation in predicting collegiate athlete baseline neurocognitive scores. J Int Neuropsychol Soc. 2018;24(1):1-10.

21. Lyons TW, Miller KA, Miller AF, Mannix R. Racial and ethnic differences in emergency department utilization and diagnosis for sports-related head injuries. Front Neurol. 2019; 10:690.

22. Deichman JJ, Graves JM, Klein TA, Mackelprang JL. Characteristics of youth who leave the emergency department without being seen following sports-related concussion. Concussion. 2019;4(4):CNC68.

23. Zuckerman SL, Zalneraitis BH, Totten DJ, et al. Socioeconomic status and outcomes after sport-related concussion: a preliminary investigation. J Neurosurg Pediatr. 2017;19(6): 652-661.

24. McCrory P, Meeuwisse WH, Aubry M, et al. Consensus statement on concussion in sport: the 4th International Conference on Concussion in Sport, Zurich, November 2012. $J$ Athl Train. 2013;48(4):554-575.
25. Rice SG. Medical conditions affecting sports participation. Pediatrics. 2008;121(4):841-848.

26. Peduzzi P, Concato J, Kemper E, et al. A simulation study of the number of events per variable in logistic regression analysis. J Clin Epidemiol. 1996;49(12):1373-1379.

27. Holmes L Jr, Tworig J, Casini J, et al. Implication of sociodemographics on cognitive-related symptoms in sports concussion among children. Sports Med Open. 2016;2(1):38.

28. Zemek R, Barrowman N, Freedman SB, et al. Clinical risk score for persistent postconcussion symptoms among children with acute concussion in the ED. JAMA. 2016;315(10): 1014-1025.

29. Ledoux AA, Tang K, Yeates KO, et al. Natural progression of symptom change and recovery from concussion in a pediatric population. JAMA Pediatr. 2019;173(1):e183820.

30. Aggarwal SS, Ott SD, Padhye NS, Schulz PE. Sex, race, ADHD, and prior concussions as predictors of concussion recovery in adolescents. Brain Inj. 2020;34(6):809-817.

31. Leddy JJ, Haider MN, Ellis MJ, et al. Early subthreshold aerobic exercise for sport-related concussion: a randomized clinical trial. JAMA Pediatr. 2019;173(4):319-325.

32. Wallace J, Covassin T, Moran R. Racial disparities in concussion knowledge and symptom recognition in American adolescent athletes. J Racial Ethn Health Disparities. 2018; 5(1):221-228.

33. Wallace J, McAllister Deitrick J, Martin T, Moran RN. Investigating disparities in high school athletes' attitude toward concussion and predictors of continuing play. J Health Dispar Res Pract. 2020;13(2):2.

34. Wallace J, Bretzin A, Beidler E, et al. The underreporting of concussion: differences between black and white high school athletes likely stemming from inequities. J Racial Ethn Health Disparities. Published online September 14, 2020. doi:10.1007/s40615-020-00864-x

35. Wallace J, Moran R, Bretzin A, et al. Examination of racial disparities in adolescents seen in the emergency department for head, neck, or brain injury. J Emerg Med. 2020;59(6): 783-794.

36. Kasamatsu T, Cleary M, Bennett J, et al. Examining academic support after concussion for the adolescent student-athlete: perspectives of the athletic trainer. $J$ Athl Train. 2016;51(2): 153-161.

37. McAvoy K, Eagan-Johnson B, Dymacek R, et al. Establishing consensus for essential elements in returning to learn following a concussion. $J$ Sch Health. 2020;90(11):849-858.

38. Lumba-Brown A, Yeates KO, Sarmiento K, et al. Centers for Disease Control and Prevention guideline on the diagnosis and management of mild traumatic brain injury among children. JAMA Pediatr. 2018;172(11):e182853.

39. Baker JG, Leddy JJ, Darling SR, et al. Factors associated with problems for adolescents returning to the classroom after sport-related concussion. Clin Pediatr (Phila). 2015; 54(10):961-968.

40. DeMatteo CA, Randall S, Lin CA, Claridge EA. What comes first: return to school or return to activity for youth after concussion? Maybe we don't have to choose. Front Neurol. 2019; 10:792.

41. McCrory P, Meeuwisse W, Dvořák J, et al. Consensus statement on concussion in sport-the $5^{\text {th }}$ International Conference on Concussion in Sport held in Berlin, October 2016. Br J Sports Med. 2017;51(11):838-847.

42. Watt TT, Martinez-Ramos G, Majumdar D. Race/ethnicity, acculturation, and sex differences in the relationship between parental social support and children's overweight and obesity. J Health Care Poor Underserved. 2012;23(4):1793-1805.

43. Hodges A, Ameringer S. The symptom experience of adolescents with concussion. J Spec Pediatr Nurs. 2019;24(4): e12271.

44. Eisenberg MA, Meehan WP III, Mannix R. Duration and 
course of post-concussive symptoms. Pediatrics. 2014;133(6): 999-1006.

45. US Census Bureau. Census.gov. Accessed April 16, 2021. https://www.census.gov/

\section{Disclosures}

Dr. Yengo-Kahn holds a compensated position on the Scientific Advisory Board of BlinkTBI. This company had no role in the design or execution of this study or the reporting of results.

BlinkTBI products were not used in the conduct of this study.

\section{Author Contributions}

Conception and design: Yengo-Kahn, Wallace, Bonfield.

Acquisition of data: Totten, Zuckerman. Analysis and interpretation of data: Yengo-Kahn, Wallace, Jimenez, Zuckerman. Drafting the article: Yengo-Kahn, Wallace, Jimenez. Critically revising the article: all authors. Reviewed submitted version of manuscript: all authors. Approved the final version of the manuscript on behalf of all authors: Yengo-Kahn. Statistical analysis: Yengo-Kahn. Study supervision: Yengo-Kahn, Bonfield, Zuckerman.

\section{Correspondence}

Aaron M. Yengo-Kahn: Vanderbilt University Medical Center, Nashville,TN. a.yengo@vumc.org. 